\title{
CKI, there's more than one: casein kinase I family members in Wnt and Hedgehog signaling
}

\author{
Mary Ann Price ${ }^{1}$ \\ Centre for Developmental and Biomedical Genetics, Department of Biomedical Science, University of Sheffield, \\ Sheffield S10 2TN, United Kingdom
}

Multiple members of the casein kinase I family of serine/threonine protein kinases are involved in positive and negative roles in Wnt and Hedgehog signaling. Here I review these roles, including recent results on casein kinase I (CKI) phosphorylation and activation of LRP6, and CKI phosphorylation of $\mathrm{Ci}$ and mediation of $\mathrm{Ci}-$ Slimb/ $\beta$-TrCP binding.

\section{Introduction to casein kinase I (CKI)}

The CKI family of serine/threonine protein kinases is involved in many diverse and important cellular functions, such as regulation of membrane transport, cell division, DNA repair, circadian rhythms, and nuclear localization (for review, see Gross and Anderson 1998; Knippschild et al. 2005). Work in the last 7 years has shown a role for multiple CKI family members in both positively and negatively regulating Wnt and Hedgehog (Hh) signaling.

The CKI family of monomeric serine-threonine protein kinases is found in eukaryotic organisms from yeast to human. Mammals have seven family members (sometimes referred to as isoforms, but encoded by distinct genes): $\alpha, \beta, \gamma 1, \gamma 2, \gamma 3, \delta$, and $\varepsilon$. The family members have the highest homology in their kinase domains (53\%-98\% identical) and differ from most other protein kinases by the presence of the sequence S-I-N instead of A-P-E in kinase domain VIII (Hanks and Hunter 1995). Outside of the kinase domain, CKI family members fall into subfamilies that have little homology to each other and differ in the length and amino acid sequence of their $\mathrm{N}$ - and C-terminal extensions. CKI $\alpha$ and CKI $\beta$ are $76 \%$ identical outside their kinase domains, the CKI $\gamma$ isoforms are $\sim 50 \%$ identical in their C-terminal tails, and the long C-terminal extensions of CKI $\delta$ and CKI $\varepsilon$ have $\sim 53 \%$ identity. In general, kinases in the family are constitutively active. The long C-terminal extensions of CKI $\delta$ and CKI $\varepsilon$, however, are autophosphorylated, and

[Keywords: Casein kinase I; Wnt signaling; Hedgehog signaling] ${ }^{1}$ Correspondence.

E-MAIL m.a.price@sheffield.ac.uk; FAX 44-0-114 276-5413.

Article and publication are at http://www.genesdev.org/cgi/doi/10.1101/ gad.1394306. this phosphorylation inhibits the activity of the kinase domain, although in vivo phosphatases keep it constitutively active in many cases (Rivers et al. 1998). Drosophila has eight CKI family members, and Caenorhabditis elegans has 87 (Plowman et al. 1999; Morrison et al. 2000).

The family members appear to have similar substrate specificity in vitro (Pulgar et al. 1999), and substrate selection is thought to be regulated in vivo via subcellular localization and docking sites in specific substrates. One consensus phosphorylation site is $\mathrm{S} / \mathrm{Tp}-\mathrm{X}-\mathrm{X}-\mathrm{S} / \mathrm{T}$, where $\mathrm{S} / \mathrm{Tp}$ refers to a phospho-serine or phospho-threonine, $\mathrm{X}$ refers to any amino acid, and the underlined residues refer to the target site (Flotow and Roach 1989; Flotow et al. 1990). Thus, this CKI consensus site requires priming by another kinase. CKI also phosphorylates a related unprimed site, which optimally contains a cluster of acidic amino acids $\mathrm{N}$-terminal to the target $\mathrm{S} / \mathrm{T}$ including an acidic residue at $n-3$ and a hydrophobic region $\mathrm{C}$-terminal to the target S/T (Flotow and Roach 1991; Pulgar et al. 1999). A single acidic residue in the $n-3$ position is not sufficient for CKI phosphorylation. In contrast, in several important targets, NF-AT (Zhu et al. 1998) and $\beta$-catenin (Amit et al. 2002; Liu et al. 2002), CKI does not require $n-3$ priming but, instead, phosphorylates the first serine in the sequence S-L-S, which is followed by a cluster of acidic residues, albeit less efficiently than the optimal sites (Marin et al. 2003).

\section{Summaries of Wnt and Hh signaling}

Both the Wnt and Hh signaling pathways are important in many developmental patterning events (for review, see Ingham and McMahon 2001; Logan and Nusse 2004). Both have also been implicated in the regulation of stem cell identity and in the initiation and maintenance of many types of tumors (Taipale and Beachy 2001; Pasca di Magliano and Hebrok 2003; Reya and Clevers 2005).

A key feature of Wnt signaling is the regulation of the stability of cytoplasmic $\beta$-catenin (Armadillo [Arm] in Drosophila), which acts as a transcriptional coactivator in the pathway (Fig. 1A, $\mathrm{A}^{\prime}$; for review, see Logan and Nusse 2004). In addition to its role in Wnt signaling, $\beta$-catenin is also a component of adherens junctions and 


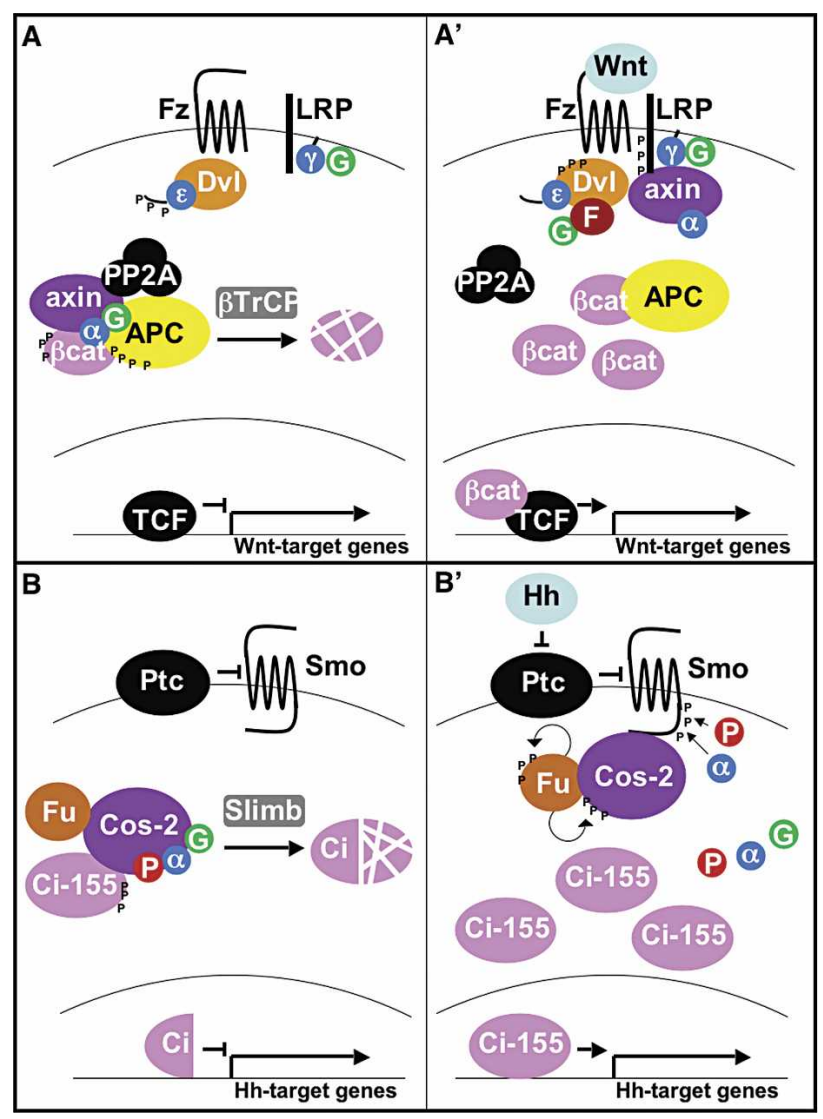

Figure 1. Models of Wnt $\left(A, A^{\prime}\right)$ and $H h\left(B, B^{\prime}\right)$ signaling. $(A)$ In the absence of Wnt ligand, $\beta$-catentin ( $\beta$-cat) is polyubiquitinated and degraded (see text for details). This degradation requires axin and $\mathrm{APC}$, and requires phosphorylation of $\beta$-catenin by CKI $\alpha(\alpha)$ and GSK3 $\beta(G)$. $\left(A^{\prime}\right)$ Upon binding of Wnt to its coreceptors $\mathrm{Fz}$ and LRP5/6, $(1) \mathrm{CKI} \varepsilon(\varepsilon)$ is activated by removal of inhibitory phosphates and DVl becomes phosphorylated, increasing its interaction with GBP/Frat $(\mathrm{F})$, which binds to and inhibits GSK3 activity, resulting in stabilization of $\beta$-catenin; (2) LRP becomes phosphorylated by CKI $\gamma(\gamma)$, increasing its interaction with axin; and (3) $\beta$-catenin migrates to the nucleus where it complexes with LEF/TCF to activate expression of Wnt-target genes. $(B)$ In the absence of $\mathrm{Hh}$, full-length $\mathrm{Ci}$ (Ci155 ) is partially degraded to Ci-75 (Ci), a shorter repressor form (see text for details). This processing requires Cos-2 and Fused, and phosphorylation of Ci by three kinases: PKA (P), GSK3 (G), and CKI $\alpha(\alpha)$. Ptc keeps Smo inactive by down-regulating its protein levels and its localization to the plasma membrane. $\left(B^{\prime}\right)$ When Hh binds to its receptor Ptc, Smo becomes phosphorylated by PKA and CKI $\alpha$, Smo levels increase, and it accumulates on the cell surface. The three kinases are released from Cos-2 (which now binds Smo), and Ci-155 accumulates, translocates to the nucleus, and activates Hh-target genes.

is involved in cell-cell adhesion via its interaction with the cytoplasmic domain of classical cadherins. In the absence of Wnt signal (Fig. 1A), protein levels of $\beta$-catenin in the cytoplasmic pool are kept low by a degradation complex made up of the tumor suppressors axin and adenomatous polyposis coli (APC), and the enzymes glycogen synthase kinase $3 \beta$ (GSK3 $\beta$ ) and protein phosphatase $2 \mathrm{~A}$ (PP2A). GSK3 $\beta$ phosphorylates $\beta$-catenin, which is then recognized by the F-box protein $\beta$-TrCP, a component of an SCF (Skp1-Cullin-F-box) E3 ubiquitin ligase. $\beta$-Catenin is then polyubiquitinated and degraded by the proteasome. In the nucleus, Wnt target genes are kept inactive by a family of high mobility group (HMG) transcription factors, Lymphocyte enhancer factor/Tcell factor (LEF/TCF). When a Wnt ligand binds to its cell surface receptor comprising the seven-pass transmembrane protein Frizzled (Fz) and LRP (LDL receptor-related protein) 5/6 (Fig. 1 $\mathrm{A}^{\prime}$ ), the signal is transduced intracellularly by Dishevelled (Dvl-1, Dvl-2, and Dvl-3 in vertebrates; Dsh in Drosophila). Dvl interacts with $\mathrm{Fz}$ and through an unknown mechanism becomes activated and blocks the degradation of $\beta$-catenin, perhaps (although not solely) (van Amerongen et al. 2005) by bringing the cellular GSK3 inhibitor GBP/Frat into the degradation complex. Furthermore, upon Wnt signaling, axin is recruited to the membrane by interaction with LRP5/6, which contributes to $\beta$-catenin stabilization $(\mathrm{He}$ et al. 2004). $\beta$-Catenin accumulates in response to Wnt signal, and it migrates to the nucleus, where it complexes with LEF/TCF and activates expression of Wnt target genes.

Hh signaling shares many features with Wnt signaling (Fig. 1B,B'; Kalderon 2002). Again, the regulation of a transcriptional activator, in this case Cubitus interruptus (Ci; Gli proteins in vertebrates), is critical for signaling (for review, see Hooper and Scott 2005). In the absence of $\mathrm{Hh}$ (Fig. 1B), full-length Ci (Ci-155) is partially degraded, leaving the $\mathrm{N}$-terminal half of the protein intact (Ci-75). Ci-75 translocates to the nucleus, where it represses transcription of some Hh target genes (AzaBlanc et al. 1997; Methot and Basler 1999). The partial degradation of $\mathrm{Ci}$ is promoted by phosphorylation and by a cytoplasmic complex, which includes Costal-2 (Cos-2), a microtubule-binding protein thought to act as a scaffold, and Fused, a serine-threonine protein kinase. As with the degradation of $\beta$-catenin, phosphorylation of $\mathrm{Ci}$ targets it for binding by Supernumerary limbs (Slimb), the Drosophila homolog of $\beta-\operatorname{TrCP}$ (Dai et al. 2003; Jia et al. 2005), leading to ubiquitination by the SCF E3 ubiquitin ligase and partial proteolysis by the proteasome. The Hh signal is transduced by a seven-pass transmembrane protein, Smoothened (Smo). In the absence of $\mathrm{Hh}$ signaling, Patched (Ptc), a 12-pass transmembrane protein, inactivates Smo by keeping its protein levels low and by preventing it from reaching the cell surface. When $\mathrm{Hh}$ binds its receptor Ptc (Fig. 1B'), this inhibition is relieved, and Smo accumulates on the cell surface and interacts with Cos-2, resulting in inhibition of Ci cleavage and conversion of Ci-155 to a more potent transcriptional activator. This further activation of Ci-155 at least partially involves Hh pathway stimulation of Ci nuclear localization by reversing the action of Cos-2 and Suppressor of fused $[\mathrm{Su}(\mathrm{fu})]$, which tether $\mathrm{Ci}$ in the cytoplasm.

\section{Positive regulation of Wnt signaling by CKI}

The Wnt signaling pathway is required for dorsal-ventral axis formation in Xenopus embryos (Moon et al. 1997). 
Injection of Wnts, or positively acting components of the Wnt pathway, into the ventral side of the embryo leads to dorsalization and duplication of the axis. The first report of CKI involvement in Wnt signaling came in 1999 with the results of expression library screens for genes that cause axis duplication in Xenopus embryos. Injection of $\mathrm{CKI} \varepsilon \mathrm{mRNA}$ led to axis duplication, rescue of primary axis formation in UV-irradiated embryos, and expression of the Wnt target genes Siamois and Xnr3 in the ventral marginal zone and in animal caps (Peters et al. 1999; Sakanaka et al. 1999). Some laboratories find that only CKI $\varepsilon$ and the close relative CKI $\delta$ have this activity (Sakanaka et al. 1999), while other labatories find that CKI $\alpha$ and, to a lesser extent, CKI $\gamma$ also cause secondary axis formation (Grammer et al. 2000; McKay et al. 2001a). In the Drosophila Kc cell line, overexpression of double-time $(d b t)$, the sole Drosophila CKI $/ \varepsilon$ gene, but not $\mathrm{CKI} \alpha$, activated a Wingless $(\mathrm{Wg}$, Drosophila Wnt) transcriptional reporter in the absence of ligand (Lum et al. 2003).

Consistent with a positive role for $\mathrm{CKI} \varepsilon$ in Wnt signaling, expression of CKI $\varepsilon$ stabilizes $\beta$-catenin in Xenopus embryos and HEK 293 cells and Arm in Drosophila S2 cells (Peters et al. 1999; Sakanaka et al. 1999). Addition of $\mathrm{CKI} \varepsilon$ blocked degradation of $\beta$-catenin in a Xenopus extract assay (Gao et al. 2002). Furthermore, expression of CKI $\varepsilon$ led to stimulation of transcription from a Lef-1 reporter construct in 293 cells (Sakanaka et al. 1999).

These are overexpression, gain-of-function experiments. Does loss of CKI $\varepsilon$ activity block Wnt signaling? In Xenopus and cell culture experiments, this question has been addressed extensively using kinase-dead, dominant-negative forms of the kinase and specific small molecule inhibitors of CKI, CKI-7 (Chijiwa et al. 1989) and IC261 (Mashhoon et al. 2000). These studies find that, indeed, blocking CKI activity blocks Wnt-induced secondary axis formation and expression of target genes in Wnt-induced animal caps (Peters et al. 1999). Support for a positive role for CKI in Wnt signaling also comes from the partial block of Wnt-induced $\beta$-catenin accumulation in NIH 3T3s by CKI-7 (McKay et al. 2001a) and the block of Wnt-induced activation of a Lef-1 reporter construct in 293 cells by kinase-dead CKIع (Sakanaka et al. 1999).

A role for CKI in primary axis formation is less clear. Neither kinase-dead forms of CKI $\varepsilon$ nor CKI-7 had an effect on primary axis formation when injected in one-cellstage Xenopus embryos. Instead, injection of kinase-dead $\mathrm{CKI} \varepsilon$ into early Xenopus embryos caused defects in convergent extension during gastrulation (McKay et al. $2001 b$ ), a process that requires some of the same components as canonical Wnt signaling. Although CKI is not the only Wnt component whose inhibition does not lead to defects in primary axis formation (Weaver and Kimelman 2004), it is possible that CKI does not play a central role in Wnt signaling in this context.

It is likely that kinase-dead CKI $\varepsilon$ mutants and the CKI inhibitors block other family members in addition to CKI $\varepsilon$ (although see Davidson et al. 2005); thus it remains possible that the positive effects on Wnt signaling are mediated by a CKI other than or in addition to CKIE. Antisense oligos and double-stranded RNA interference (RNAi) have also been used to knock down expression of specific CKI family members. CKI $\varepsilon$ antisense oligonucleotides and RNAi against $\mathrm{CKI} \varepsilon$, but not $\mathrm{CKI} \alpha$, inhibited Wnt signaling, as indicated by transcriptional reporter assays and $\beta$-catenin levels (Sakanaka et al. 1999; Hino et al. 2003). Similarly, Cong et al. (2004) found that $d b t / C K I \varepsilon$ RNAi in Drosophila S2 cells significantly reduced $\mathrm{Wg} / \mathrm{Dfz} 2$ induction of transcription of a Lef1-luciferase reporter construct. However, two groups found that $d b t / \mathrm{CKI} \varepsilon$ double-stranded RNA (dsRNA) had no effect on $\mathrm{Wg}$ induction of transcription in Drosophila cells, and, in fact, RNAi of none of the CKI family members inhibited Wg-induced reporter activity (Lum et al. 2003; DasGupta et al. 2005; although see below and Davidson et al. 2005). Recent results show that mouse embryo fibroblasts lacking CKI $\varepsilon$ exhibit normal Wnt signaling (Zeng et al. 2005), suggesting that in both Drosophila and vertebrates there may be redundancy between CKI family members in the activation of Wnt signaling.

\section{Potential targets of CKI in the positive regulation of Wnt signaling}

\section{Dishevelled}

A large body of evidence suggests that Dvl is an important target for positive regulation of Wnt signaling by CKI. Dvl interacts with CKI $\varepsilon$ via either the PDZ or DEP domain of Dvl (Fig. 2; Peters et al. 1999; Sakanaka et al. 1999; Kishida et al. 2001; Gao et al. 2002). CKI $\varepsilon$ phosphorylates Dvl in vitro, in Xenopus oocytes, and in Cos cells (Peters et al. 1999; Kishida et al. 2001; McKay et al. 2001a; Gao et al. 2002; Hino et al. 2003). CKI $\varepsilon$ phosphorylation leads to a shift in mobility of Dvl on SDSpolyacrylamide gels, similar to that seen in response to Wnt signaling (Yanagawa et al. 1995; McKay et al. 2001a). As with Wnt signaling, the shift caused by CKI $\varepsilon$ requires the PDZ domain of Dvl (McKay et al. 2001a). Importantly, CKI-7 and CKI $\varepsilon$ RNAi block the mobility shift of Dsh caused by Wnt3a treatment in several cell lines (McKay et al. 2001a; Hino et al. 2003). These results suggest that $\mathrm{CKI} \varepsilon$ (and perhaps CKI $\alpha$ in Drosophila) (Matsubayashi et al. 2004) phosphorylates Dvl upon Wnt induction.

CKI $\varepsilon$ appears to phosphorylate Dvl on multiple sites. A fragment containing the region spanning the PDZ and DEP domains (amino acids 231-531) and smaller fragments (amino acids 221-360 and 371-500) are phosphorylated by CKI $\varepsilon$ in vitro (Peters et al. 1999; McKay et al. 2001a; Cong et al. 2004). Which specific residues in Dvl are phosphorylated by CKI $\varepsilon$ ? Results with mutants in which three sites in the DEP domain or one site in the PDZ domain are changed to $\mathrm{D}$, a negatively charged phospho-mimetic residue, were consistent with these sites being phosphorylated by CKI; however, mutants in which these residues were changed to $\mathrm{A}$, a residue which cannot be phosphorylated, were still responsive to Wnt 


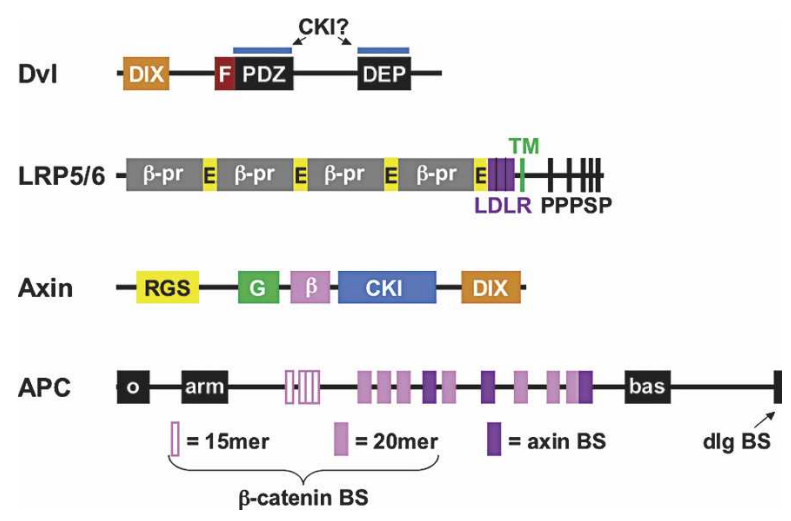

Figure 2. Schematics of Dishevelled, LRP5/6, Axin, and APC. Dishevelled contains a DIX domain (which binds Axin), a GBP/ Frat-binding domain (F), a PDZ domain, and a DEP domain. CKI has been reported to bind either the PDZ or DEP domain. LRP5/6 contains four YWTD-type $\beta$-propeller domains ( $\beta$-pr), each followed by an EGF-like domain (E), three LDLR type-A domains (LDLR), a transmembrane domain (TM), and five PPPSP motifs. Axin contains the following domains: RGS (which binds APC), a GSK3-binding domain $(G)$, a $\beta$-cateninbinding domain $(\beta)$, a CKI-binding domain, and a DIX domain (which binds Dvl). APC contains an oligomerization domain (o), an armadillo repeat region (arm), four 15-mer repeats (which bind $\beta$-catenin), seven 20 -mer repeats (which also bind $\beta$-catenin), three axin-binding sites, a basic region (bas), and a discs-large-binding site (dlg BS).

signaling, indicating that these are not the only CKI phosphorylation sites in Dvl (Cong et al. 2004).

How might phosphorylation of Dvl by CKIe lead to activation of the Wnt pathway? Dvl is thought to activate Wnt signaling by recruiting GBP /GSK3-binding protein)/Frat to the $\beta$-catenin destruction complex (Yost et al. 1998; Lee et al. 1999; Li et al. 1999|, thereby inhibiting GSK3 $\beta$ and blocking $\beta$-catenin degradation. Several groups have reported that $\mathrm{CKI} \varepsilon$ enhances binding of GBP/Frat to Dvl (Lee et al. 2001; Hino et al. 2003). Coexpression of Dvl caused Frat, normally distributed throughout the cytoplasm, to colocalize in a punctate pattern. The redistribution of Frat by Dvl can be blocked by $\mathrm{CKI} \varepsilon$, but not CKI $\alpha$, RNAi, or by deletion of the Fratbinding domain in Dvl (Hino et al. 2003). Kinase-dead $\mathrm{CKI} \varepsilon$ partially blocks the Frat enhancement of Dvl-induced Lef-1 reporter activity, whereas wild-type CKI $\varepsilon$ further enhances it (Hino et al. 2003). These results suggest that the enhancement of the of Dvl-Frat interaction by CKI $\varepsilon$ is important for Dvl function and Wnt signaling; however, it is not clear whether direct CKI $\varepsilon$ phosphorylation of the Frat-binding region of Dvl leads to the increase in the Dvl-Frat interaction. It is worth noting that the region of Dvl required for the Dvl-Frat interaction is included in small fragments that are phosphorylated by CKI $\varepsilon$ (Peters et al. 1999; McKay et al. 2001a; Cong et al. 2004).

\section{$L E F / T C F$}

TCF3 has also been suggested to be the target of CKI $\varepsilon$ phosphorylation in the positive regulation of Wnt signal- ing (Lee et al. 2001). CKI $\varepsilon$ binds to and phosphorylates TCF3; this phosphorylation increases the affinity of TCF3 for $\beta$-catenin and its ability to compete with axin and APC for $\beta$-catenin binding. In an assay in Xenopus extracts, CKI $\varepsilon$ enhances, and CKI-7 reduces, the ability of TCF3 to stabilize $\beta$-catenin (Lee et al. 2001). The generality of this result, however, has been brought into doubt by results that suggest that CKI phosphorylation of another family member, Lef-1, in fact, disrupts its binding to $\beta$-catenin (Hammerlein et al. 2005).

\section{The degradation complex}

CKI may also positively regulate Wnt signaling by destabilizing the $\beta$-catenin degradation complex (Gao et al. 2002). Heterotrimeric PP2A, made up of A, B, and C subunits, binds to the degradation complex via axin and APC and negatively regulates Wnt signaling by dephosphorylating an unknown target (Hsu et al. 1999; Seeling et al. 1999). In an in vitro assay, the amount of PP2A C and A subunits bound to either myc-axin or myc- $\beta$ catenin was reduced if the extract was first incubated with $\mathrm{CKI} \varepsilon$, while incubation with kinase-dead CKI $\varepsilon$ and CKI-7 (or pretreatment of cells with CKI inhibitor IC261) resulted in increased PP2A C and A bound to axin and $\beta$-catenin (Gao et al. 2002). These results suggest that $\mathrm{CKI} \varepsilon$ activity reduces inclusion of $\mathrm{PP} 2 \mathrm{~A}$ in the $\beta$-catenin degradation complex, resulting in $\beta$-catenin accumulation and in Wnt target gene expression. However, it is not clear which component of the degradation complex is directly phosphorylated by CKI $\varepsilon$ to mediate this effect.

\section{LRP6}

Recently CKI has been shown to positively regulate Wnt signaling by phosphorylating LRP6 (Fig. 2; Davidson et al. 2005; Zeng et al. 2005). CKI $\gamma$ was identified in a small pool expression screen for proteins that covalently modify LRP6 as detected by mobility on SDS-polyacrylamide gels (Davidson et al. 2005). CKI $\gamma$, but not CKI $\varepsilon$, synergizes with LRP6 in Wnt transcriptional reporter assays. Similarly, in Drosophila SL2 cells, Gilgamesh (Gish; the sole Drosophila CKI $\gamma$ ) synergizes with Arrow (Drosophila LRP5/6) to activate a Wg transcriptional reporter. Furthermore, dominant-negative forms of CKI $\gamma$ (K73R and D173N) inhibit Wnt signaling in a reporter assay in $293 \mathrm{~T}$ cells, and gish RNAi partially blocks transcription induced by Wg in SL2 cells (Davidson et al. 2005). Zeng et al. (2005) found that a combination of dominant-negative CKI $\alpha$ and CKI $\delta$ blocked phosphorylation of a CKI site in LRP6 in response to Wnt treatment; however, it is possible that these inhibitors affect CKI $\gamma$ activity.

Unique among CKI family members, CKI $\gamma$ is anchored in the membrane via a C-terminal palmitoylation site, and this site is required for interaction with LRP6 and for synergy between CKI $\gamma$ and LRP6 in the transcription assay (Davidson et al. 2005).

LRP5, LRP6, and Arrow contain five P-P-P-S-P motifs, 
which mediate axin binding (Tamai et al. 2004) and have been recently shown to be phosphorylated by GSK3 (Zeng et al. 2005). Each of these P-P-P-S-P motifs in LRP6 is followed by at least one potential GSK3-primed CKI site (Fig. 3; Zeng et al. 2005). Phosphorylation of LRP6 by both GSK3 and CKI is required for axin binding in vitro (Zeng et al. 2005), and treatment of cells with kinasedead CKI $\gamma$ blocks coimmunoprecipitation of axin with LRP6 (Davidson et al. 2005). In the context of a single motif, serines and threonines on both sides of the PPPSP motif are required for binding to axin and for activation of transcription from a Lef1-dependent reporter (Davidson et al. 2005; Zeng et al. 2005). In the context of the full-length cytoplasmic domain, mutation of all five GSK3-primed CKI sites blocks the activity of LRP6 in $\mathrm{TCF} / \beta$-catenin reporter assays and prevents axin binding (Zeng et al. 2005). It is at present unclear if Wnt signaling induces GSK3 phosphorylation of PPPSP motifs (Tamai et al. 2004; Zeng et al. 2005) or if GSK3 phosphorylation is constitutive and Wnt induces CKI $\gamma$ phosphorylation of LRP, including at sites like T1479, which is apparently not primed by GSK3 (Davidson et al. 2005). Taken together, these results suggest that GSK3 and CKI $\gamma$ phosphorylate LRP6 in response to Wnt signaling and that this phosphorylation is required for axin binding and the activation of Wnt target genes.

\section{Negative regulation of Wnt signaling by CKI family members}

\section{$\beta$-Catenin}

GSK3 $\beta$ phosphorylation of $\beta$-catenin creates an optimal $\beta$-TrCP-binding site encompassing S33 and S37 (Fig. 3),

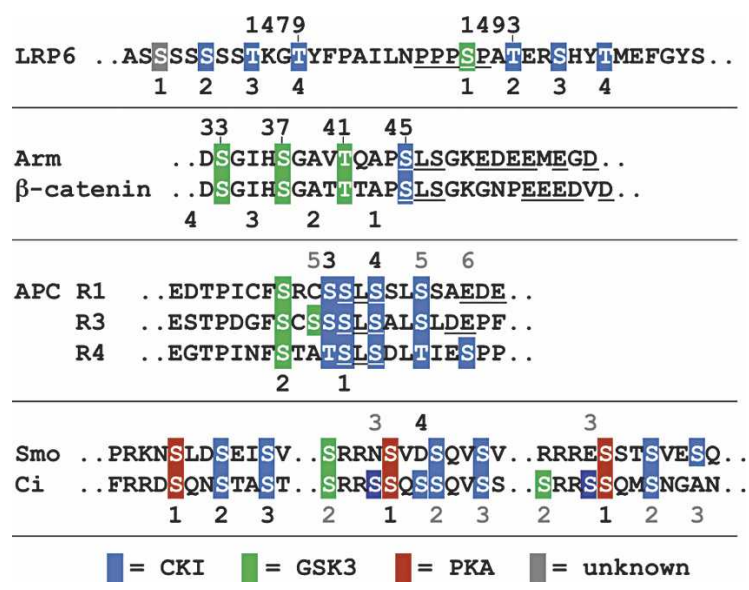

Figure 3. CKI phosphorylation sites in Wnt and Hh components. The underlined sequences in APC R1, R3, and R4 (the first, third, and fourth 20-mer repeats); $\beta$-catenin; and Arm indicate the unusual CKI consensus sequence (S-L-S followed by a C-terminal acidic cluster). The underlined sequence in LRP6 is the PPPSP motif. In each case, the numbers indicate the order of phosphorylation where priming is required. (Blue boxes) CKI phosphorylation sites; (green boxes) GSK3; (red boxes) PKA; (gray boxes) an unknown kinase. (The left cluster of phosphorylation sites in LRP6 is hypothetical, although it is known that T1479 is phosphorylated in response to Wnt-signaling.) leading to the ubiquitination and degradation of $\beta$-catenin by the proteasome (Winston et al. 1999). In many targets, GSK3 $\beta$ phosphorylation is primed by a phospho-serine or phospho-threonine at the $n+4$ position (S/T-X-X-X-S/Tp), as in $\beta$-catenin sites T41, S37, and S33, once S45 is phosphorylated. While it was initially thought that GSK3 $\beta$ phosphorylates unprimed S45, in 2002 two laboratories showed that CKI phosphorylates $\beta$-catenin at S45, priming GSK3 $\beta$ phosphorylation (Amit et al. 2002; Liu et al. 2002). Using antibodies specific for phosphorylation sites in the $\mathrm{N}$-terminal tail of $\beta$-catenin, both groups found that overexpression or inhibition of GSK3 had the expected effect on phosphorylation of S33, S37, and T41, but neither had an effect on phosphorylation of S45. Both groups found that phosphorylation of S45 was induced by wild-type axin and an axin mutant that does not bind GSK3, suggesting that the S45 kinase is something other than GSK3. Using mass spectrometry, it was found that axin interacts with five kinases, GSK3 $\alpha$, GSK3 $\beta$, CKI $\varepsilon$, CKI $\delta$, and CKI $\alpha$ (Amit et al. 2002), and that a purified $\mathrm{S} 45$ phosphorylating activity from rat brain extract is CKI $\alpha$ (Liu et al. 2002). While both CKI $\alpha$ and $\mathrm{CKI} \varepsilon$ interact with axin and the $\mathrm{CKI} \varepsilon$ relative CKI can phosphorylate $\beta$-catenin in vitro (Amit et al. 2002), some results suggest that $\mathrm{CKI} \alpha$ is the $\beta$-catenin kinase in vivo. Overexpression of $\mathrm{CKI} \alpha$, but not $\mathrm{CKI} \varepsilon$, leads to phosphorylation of S45 in vivo (Liu et al. 2002). CKI $\alpha$ RNAi, but not CKI $\varepsilon$ RNAi, inhibited S45 (and S33, S37, and T41) phosphorylation in 293T cells (Liu et al. 2002) and resulted in increased $\beta$-catenin/Arm levels in the absence of Wnt $/ \mathrm{Wg}$ in vertebrate and Drosophila cells (Liu et al. 2002; Yanagawa et al. 2002; Hino et al. 2003; Matsubayashi et al. 2004). Injection of double-stranded CKI $\alpha$ RNA in Drosophila embryos led to a naked cuticle phenotype and expansion of stripes of wg and engrailed expression (Liu et al. 2002; Yanagawa et al. 2002; Lum et al. 2003), the expected results for ligand-independent activation of Wg signaling. Consistent with this, an RNAi screen in Drosophila cultured cells identified CKI $\alpha$ (and a second CKI $\alpha$-related kinase, CG2577), but not $d b t /$ $\mathrm{CKI} \varepsilon$, as a regulator of $\mathrm{Wg}$ reporter activity in the absence of Wg (Lum et al. 2003; DasGupta et al. 2005).

Thus CKI $\alpha$ phosphorylates $\beta$-catenin, priming phosphorylation by GSK3 $\beta$ at three sites (Fig. 3) and leading to $\beta$-catenin degradation. But is CKI $\alpha$ phosphorylation of $\beta$-catenin primed? Apparently, the sequence S-L-S followed by a stretch of acidic residues can be phosphorylated by CKI without priming (Marin et al. 2003). A mutant in which the six acidic residues $\mathrm{C}$-terminal to the S-L-S motif in $\beta$-catenin were changed (ED to QN) was more stable than wild-type $\beta$-catenin, and was only weakly stabilized further by CKI $\alpha$ RNAi (Yanagawa et al. 2002). Mutation of the three GSK3 $\beta$ sites, the CKI $\alpha$ site, and these acidic residues have been found in human cancers (Polakis 1999, 2002).

\section{$A P C$}

APC (Fig. 2) is phosphorylated in vitro by CKI $\delta$ and CKI $\varepsilon$ (Kishida et al. 2001; Gao et al. 2002; Xing et al. 2003; Ha 
et al. 2004). A proposed phosphorylation scheme for the seven 20-mer repeats in APC is shown in Figure 3 (Ha et al. 2004). APC has been suggested as a target for negative regulation of Wnt signaling by CKI (Rubinfeld et al. 2001). A fragment of APC containing two 15-amino-acid repeats, two 20-amino-acid repeats /which bind $\beta$-catenin), and an axin-binding site, undergoes axin-dependent phosphorylation in vivo, and this phosphorylation is blocked by kinase-dead CKI $\varepsilon$ or CKI-7. Expression of this fragment partially decreases the LEF-dependent transcriptional response in SW480 cells, and this activity is dependent on serines in the 20 -amino-acid repeats ( $\mathrm{Ru}$ binfeld et al. 2001). Biochemical and X-ray crystallographic studies show that unphosphorylated 20-mer repeats from APC bind $\beta$-catenin, but CKI- and GSK3phosphorylated 20-mer repeats bind with 300- to 500fold greater affinity, with three phosphates per repeat making direct contact with $\beta$-catenin (Ha et al. 2004; Xing et al. 2004). Phosphorylated APC 20-mer repeats compete with axin for binding to $\beta$-catenin in vitro; thus it is not clear how phosphorylation of APC enhances its down-regulation of $\beta$-catenin (Xing et al. 2003; Ha et al. 2004).

\section{Axin as a scaffold}

Axin (Fig. 2) has been suggested to act as a scaffold for all the components necessary for $\beta$-catenin degradation. $\mathrm{CKI} \varepsilon$ and axin interact in a variety of assays via a region in axin C-terminal to the $\beta$-catenin-binding site (Sakanaka et al. 1999; Kishida et al. 2001; McKay et al. 2001a; Rubinfeld et al. 2001; Gao et al. 2002). Phosphorylation of $\beta$-catenin and APC by CKI $\varepsilon$ is greatly enhanced by the presence of an axin fragment containing the $\beta$-cateninand CKI-binding sites in vitro ( $\mathrm{Ha}$ et al. 2004) and in cultured cells (Rubinfeld et al. 2001; Liu et al. 2002). Thus it appears that axin acts as a scaffold to allow efficient phosphorylation of $\beta$-catenin and APC by GSK3 $\beta$ and CKI in vivo, although this role for axin may not be conserved in Drosophila (Matsubayashi et al. 2004). Axin appears to be a substrate for CKI phosphorylation (Kishida et al. 2001; Gao et al. 2002), but the significance of this for negative or positive effects on Wnt signaling is unclear.

\section{Regulation of CKI by Wnt signaling}

Is CKI activity regulated by Wnt signaling? Dvl is phosphorylated in response to Wnt signaling, and this is at least partially due to phosphorylation by CKIs (McKay et al. 2001a; Hino et al. 2003), suggesting that Wnt may activate $\mathrm{CKI} \varepsilon$. CKI $\varepsilon$ activity increases upon Wnt stimulation in many cell types, as measured by in vitro kinase assays with immunoprecipitated $\mathrm{CKI} \varepsilon$, and this increase in CKI activity is due to Wnt activity relieving CKI $\varepsilon$ inhibitory autophosphorylation (Swiatek et al. 2004). $\mathrm{CKI} \varepsilon$ from untreated cells can be activated by phosphatase treatment, and CKI $\varepsilon$ from Wnt-induced cells can be inactivated by incubation with ATP, which allows in- hibitory autophosphorylation (Swiatek et al. 2004). Wnt coexpression with $\mathrm{CKI} \varepsilon$ led to a more basic isoelectric point, consistent with the removal of phosphates from $\mathrm{CKI} \varepsilon$. In addition, a mutant CKI $\varepsilon$ lacking the autophosphorylation sites is more active than wild type in a transcriptional reporter assay and is unresponsive to Wnt induction. Finally, inhibitors of phosphatases PP1, PP2A, and PP2B blocked Wnt activation of wild-type, but not mutant, CKI $\varepsilon$. These results are consistent with a model in which Wnt activates a phosphatase that dephosphorylates the C-terminal tail of $\mathrm{CKI} \varepsilon$, thereby activating it (Swiatek et al. 2004).

Wnt signaling may also activate CKI $\gamma$ phosphorylation of LRP6: Wnt treatment increases CKI $\gamma$ phosphorylation at T1479 (Davidson et al. 2005). However, T1479 is constitutively phosphorylated when the extracellular domain of LRP6 is deleted, suggesting that this region normally prevents CKI $\gamma$ phosphorylation of LRP in the absence of Wnt signaling and that Wnt changes the availability of LRP6 for phosphorylation rather than changing CKI $\gamma$ activity (Davidson et al. 2005). Results from Zeng et al. (2005) are also consistent with constitutive CKI $\gamma$ activity.

Whether Wnt signaling inhibits CKI $\alpha$ phosphorylation of $\beta$-catenin is unclear, due to conflicting results from several laboratories (Amit et al. 2002; Liu et al. 2002; Matsubayashi et al. 2004), possibly resulting from different lengths of Wnt treatment (Matsubayashi et al. 2004). It remains possible, therefore, that in addition to its wellknown role in inhibiting GSK3 $\beta$ activity, Wnt signaling also reduces $\mathrm{CKI} \alpha$ activity.

\section{Negative regulation of the Hedgehog pathway by CKI}

At the same time CKI was shown to have a role in $\beta$-catenin degradation, it was found that CKI plays a similar role in the partial proteolysis of $\mathrm{Ci}$ (Price and Kalderon 2002), the first example of an involvement of $\mathrm{CKI}$ in Hh signaling. Protein kinase A (PKA) phosphorylates $\mathrm{Ci}$ on five sites $\mathrm{C}$-terminal to its cleavage site, and mutation of three of these sites (Fig. 3) blocks the cleavage of full-length Ci to Ci-75 (Chen et al. 1998; Y. Chen et al. 1999; Price and Kalderon 1999). PKA phosphorylation of these three sites primes further phosphorylation of Ci by GSK3 (Jia et al. 2002; Price and Kalderon 2002) and CKI in vitro (Fig. 3; Price and Kalderon 2002). In fact, a recent paper shows that PKA-primed GSK3 phosphorylation at site 2 primes additional phosphorylation by CKI (Fig. 3; Jia et al. 2005). Mutation of either the three PKA sites or PKA-primed CKI sites prevents phosphorylation of $\mathrm{Ci}$ by CKI in vitro and blocks Ci cleavage in embryos and wing discs (Price and Kalderon 2002; Jia et al. 2005). Mutation of the PKA-primed CKI sites at site 1 or the PKA- and GSK-primed CKI sites at site 2 also completely blocked cleavage of Ci in wing discs (Jia et al. 2005). Thus, phosphorylation of $\mathrm{Ci}$ at multiple CKI sites is required for Ci processing in vivo.

How does phosphorylation of Ci target it for proteolysis? When the F-box protein Slimb $/ \beta$-TrCP was discovered to be required for $\mathrm{Ci}$ proteolysis, it was suggested 
that Slimb binds phosphorylated Ci, leading to its ubiquitination and partial proteolysis (Jiang and Struhl 1998). Direct evidence for Slimb binding to phosphorylated, but not unphosphorylated, $\mathrm{Ci}$ came from comparison of wild-type $\mathrm{Ci}$ and a PKA-site mutant in an in vitro binding assay (Dai et al. 2003). PKA-primed CKI phosphorylation is specifically required for Slimb binding in vitro (Jia et al. 2005; Smelkinson and Kalderon 2006). That mutation of single GSK3 or CKI sites leads to a partial or complete block of $\mathrm{Ci}$ proteolysis in vivo suggests that this $~ 60$-amino-acid region of Ci must become highly phosphorylated in order to be bound by Slimb and processed by the proteasome (Jia et al. 2002, 2005). This differs from $\beta$-catenin, in which a single optimal $\beta$-TrCP/Slimb-binding site (D-Sp-G-X-X-Sp) is sufficient for interaction, and is more reminiscent of F-box protein CDC4 binding of Sicl (Nash et al. 2001). In fact, introduction of an optimal Slimb-binding site in Ci at PKA site 2 is sufficient to promote Ci proteolysis in the absence of phosphorylation at the other two PKA sites (Jia et al. 2005; Smelkinson and Kalderon 2006).

Which of the eight Drosophila CKI family members is responsible for Ci proteolysis in vivo? Overexpression of $d b t / \mathrm{CKI} \varepsilon$ enhanced PKA-induced degradation of $\mathrm{Ci}$ in wing discs (Price and Kalderon 2002), and overexpression of either CKI $\alpha$ or CKI $\varepsilon$ blocked reporter transcription in response to Hh in clone 8 cells (Lum et al. 2003), consistent with, but not proving, the involvement of these CKI family members in the negative regulation of Hh signaling. In a screen of $43 \%$ of the identified genes in Drosophila, RNAi against $\mathrm{CKI} \alpha$, but not $\mathrm{CKI} \varepsilon$, led to increased basal activity from a Hh transcriptional reporter construct in Drosophila clone 8 cells (Lum et al. 2003), the expected result for a component that negatively regulates Hh signaling. Furthermore, injection of doublestranded CKI $\alpha$ in Drosophila embryos led to a naked cuticle phenotype and broadened stripes of $w g$ expression (Lum et al. 2003), phenotypes previously attributed to ectopic activation of $\mathrm{Wg}$ signaling (Liu et al. 2002; Yanagawa et al. 2002), but also consistent with activation of Hh signaling. In contrast, recent results show that in the wing disc, CKI $\alpha$ and CKI $\varepsilon$ act semiredundantly to promote Ci proteolysis (Jia et al. 2005). These results appear to reflect a real difference between wing discs and clone 8 cells (a cell line derived from wing discs), since RNAi targeted to regions unique to CKI $\alpha$ is sufficient to strongly activate $\mathrm{Hh}$ target genes in the absence of ligand in clone 8 cells (Lum et al. 2003). Whether this reflects a difference in CKI family members expressed in vivo and in cells or whether there is a difference in mechanism in these two cases is unclear. Because reagents that specifically knock out CKI $\alpha$ have not been used in experiments in Drosophila embryos, it is not clear if CKI $\alpha$ and CKI $\varepsilon$ act redundantly in this tissue. It is entirely possible that in other tissues where Hh signaling plays a role, a single CKI suffices or a different subset of CKI family members from the wing disc is involved.

Thus, $\mathrm{Ci}$ is phosphorylated by PKA at multiple sites priming phosphorylation by both GSK3 and CKI, leading to partial proteolysis. The PKA, GSK3, and CKI sites are conserved in Gli2 and Gli3, vertebrate homologs of Ci that are similarly processed (von Mering and Basler 1999; Aza-Blanc et al. 2000; B. Wang et al. 2000); in fact, both proteins have an additional potential PKA site with associated primed GSK3 and CKI sites. PKA plays a similar role in vertebrate $\mathrm{Hh}$ signaling and Gli3 processing as it does in Drosophila (Concordet et al. 1996; Hammerschmidt et al. 1996; B. Wang et al. 2000). While the role of the GSK3 and CKI sites in Gli3 has not yet been explored in vivo, it has recently been shown that Gli3 mutants lacking CKI or GSK3 phosphorylation sites are not processed to Gli3-83 (Wang and Li 2006).

\section{Positive regulation of Hh signaling by CKI}

CKI has also been implicated in positive regulation of Drosophila Hh signaling by phosphorylating Smo, the seven-pass transmembrane protein that transduces the Hh signal. In the absence of Hh signal, Smo levels are kept low and it is prevented from accumulating at the cell surface by Ptc, which is thought to regulate Smo trafficking. When Hh binds to Ptc, Smo becomes phosphorylated, its overall levels increase, and it accumulates at the cell surface (Denef et al. 2000). Therefore, while smo mRNA is expressed evenly throughout the wing disc, Smo protein levels are high in cells lacking Ptc and low in cells expressing Ptc, except where $\mathrm{Hh}$ counters Ptc function. Smo has five PKA consensus sites in its C-terminal cytoplasmic domain; three of these are associated with potential primed CKI sites and one with a GSK3 site (Fig. 3; Jia et al. 2004; Zhang et al. 2004; Apionishev et al. 2005). PKA and CKI phosphorylate Smo in vitro and in vivo (Jia et al. 2004; Zhang et al. 2004; Apionishev et al. 2005) and, importantly, these sites in Smo, as well as many others, are phosphorylated in Hh-stimulated cells (Zhang et al. 2004). Treatment of cells with PKA and CKI inhibitors blocks the mobility shift of Smo in response to Hh (Jia et al. 2004), suggesting that PKA and CKI are Smo kinases in vivo. Mutants lacking all three PKA sites or the associated CKI sites do not rescue smo function in smo mutant embryos, smo mutant clones in wing discs, or smo RNAi-treated clone 8 cells (Zhang et al. 2004; Apionishev et al. 2005; Jia et al. 2005). A mutant lacking the GSK3 site, however, behaved similarly to wild-type Smo in embryos and discs (Apionishev et al. 2005), suggesting that phosphorylation of the CKI, but not GSK3, sites is required for Smo function. Expression of double-stranded CKI $\alpha$ RNA in wing discs resulted in reduced expression of Hh target genes collier, ptc, and engrailed (Jia et al. 2004; Apionishev et al. 2005), consistent with a loss of Smo function. It should be noted, however, that this CKI $\alpha$ construct affects levels of both CKI $\alpha$ and Dbt/CKI $\varepsilon$ (Jia et al. 2005), and therefore both family members may phosphorylate and activate Smo in vivo. Taken together, these results are consistent with a positive role for CKI phosphorylation of Smo in Drosophila Hh signaling.

The effects of loss of CKI phosphorylation on Smo accumulation were less clear: Apionishev et al. (2005) found that CKI $\alpha$ RNAi increased Smo levels in ptc-ex- 
pressing cells, indicating a resistance to Ptc-dependent degradation, while Jia et al. (2004) found that CKI $\alpha$ RNAi reduced Smo levels in cells lacking Ptc and in cells expressing ptc but also receiving the Hh signal. Mutants of Smo in which PKA or CKI sites have been changed to alanine accumulate to similar levels in ptc-expressing or nonexpressing cells, although it is unclear whether these levels are similarly high (Apionishev et al. 2005) or similarly low (Jia et al. 2004). This has led Apionishev et al. to conclude that CKI phosphorylation of Smo is required for the degradation of Smo in the absence of Hh. Results from Jia et al., in contrast, suggest that CKI phosphorylation blocks Smo degradation.

Smo mutants in which phosphorylation sites have been changed to D or E, phospho-mimetic residues, activate Hh target genes in the absence of ligand in wing discs and in cultured cells, localize constitutively to the cell surface, and promote phosphorylation of $\mathrm{Fu}, \mathrm{Su}(\mathrm{fu})$, and Cos-2, known Smo-mediated responses to Hh signaling, in the absence of signal (Jia et al. 2004; Zhang et al. 2004). Hh further activates the mutants in these assays, suggesting that Smo is regulated in ways in addition to phosphorylation of these sites. Consistent with the model whereby Smo phosphorylation blocks its degradation, these mutants appear to be stabilized in the absence of Hh signaling (Jia et al. 2004; Zhang et al. 2004).

Thus, in Drosophila, CKI phosphorylation of Smo is required for Smo to transduce the Hh signal. While it is unclear how CKI phosphorylation affects Smo stability, it does appear to be necessary and sufficient for Smo localization to the plasma membrane. Vertebrate homologs of Smo do not contain these PKA and CKI sites, and therefore are presumably regulated by a different mechanism from Drosophila Smo.

\section{Regulation of CKI by Hh signaling}

Does the Hh pathway regulate CKI activity? It is known that phosphorylation of Ci-155 decreases with Hh signaling (C.H. Chen et al. 1999). This could be due to an increase in dephosphorylation of $\mathrm{Ci}$ (e.g., a Hh-induced

Table 1. Demonstrated and proposed targets of CKI in Wnt signaling

\begin{tabular}{|c|c|c|}
\hline Target & Result & References \\
\hline \multicolumn{3}{|l|}{ A. Positive roles } \\
\hline Dvl & $\begin{array}{l}\text { CKI } \varepsilon \text { binds and phosphorylates Dvl, and this phosphorylation is } \\
\text { blocked by CKI-7 and CKI } \varepsilon \text { RNAi. CKI } \varepsilon \text { and Dvl synergize in } \\
\text { activating Wnt signaling. CKI } \varepsilon \text { phosphorylation of Dvl increases its } \\
\text { affinity to GBP/Frat, and the synergy between CKI } \varepsilon \text { and Dvl is lost } \\
\text { if the GBP-binding site in Dvl is deleted. CKI } \varepsilon \text { phosphorylation also } \\
\text { appears to cause diffuse, as opposed to punctate, Dvl localization. }\end{array}$ & $\begin{array}{l}\text { Peters et al. 1999; Sakanaka et al. } \\
\text { 1999; Kishida et al. 2001; Lee et al. } \\
\text { 2001; McKay et al. 2001a; Gao et al. } \\
\text { 2002; Hino et al. 2003; Cong et al. } \\
2004\end{array}$ \\
\hline TCF3 & $\begin{array}{l}\text { CKI } \varepsilon \text { binds and phosphorylates TCF3, leading to an increase in } \\
\text { TCF- } \beta \text {-catenin interaction and to an enhancement of } \beta \text {-catenin } \\
\text { stabilization. }\end{array}$ & Lee et al. 2001 \\
\hline $\begin{array}{l}\beta \text {-Catenin } \\
\text { degradation } \\
\text { complex }\end{array}$ & $\begin{array}{l}\text { CKI } \varepsilon \text { decreases PP2A IPed with axin and } \beta \text {-catenin, while IC261 } \\
\text { increases PP2A IPed with } \beta \text {-catenin. CKI } \varepsilon \text { destabilization of the } \\
\text { degradation complex is thought to lead to increased cytoplasmic } \\
\beta \text {-catenin. }\end{array}$ & Gao et al. 2002 \\
\hline LRP5/6 & $\begin{array}{l}\text { CKI } \gamma \text { associates with and phosphorylates LRP6 on sites primed by } \\
\text { GSK3; dnCKI } \gamma \text { or dnCKI } \alpha+\text { dnCKI block in vivo phosphorylation } \\
\text { of LRP6. Mutations in CKI sites in LRP6 prevent Wnt activation. } \\
\text { CKI phosphorylation of LRP6 increases its interaction with axin, a } \\
\text { key event in activation of Wnt signaling. Wnt signaling may } \\
\text { regulate either GSK3 or CKI } \gamma \text { phosphorylation of LRP6. }\end{array}$ & Davidson et al. 2005; Zeng et al. 2005 \\
\hline \multicolumn{3}{|l|}{ B. Negative roles } \\
\hline$\beta$-Catenin & $\begin{array}{l}\text { CKI } \alpha / \delta / \varepsilon \text { phosphorylate } \beta \text {-catenin on S45; this phosphorylation is } \\
\text { blocked by CKI-7, dnCKI } \varepsilon \text {, and CKI } \alpha \text { RNAi. S45 phosphorylation } \\
\text { primes GSK3, leading to } \beta \text {-TrCP binding, and ultimately } \\
\text { degradation. Wnt signaling inhibits GSK3 phosphorylation of } \\
\beta \text {-catenin, and may inhibit CKI as well. }\end{array}$ & $\begin{array}{l}\text { Amit et al. 2002; Liu et al. 2002; } \\
\text { Yanagawa et al. } 2002\end{array}$ \\
\hline $\mathrm{APC}$ & $\begin{array}{l}\text { APC is phosphorylated by CKI } / \varepsilon \text {; phosphorylated APC has increased } \\
\beta \text {-catenin interaction and competes with axin for binding to } \\
\beta \text {-catenin. Mutations in CKI sites impair APC stimulation of } \\
\beta \text {-catenin degradation. }\end{array}$ & $\begin{array}{l}\text { Kishida et al. 2001; Rubinfeld et al. } \\
\text { 2001; Gao et al. 2002; Xing et al. } \\
\text { 2003, 2004; Ha et al. } 2004\end{array}$ \\
\hline Axin & $\begin{array}{l}\text { CKI } / \varepsilon \text { phosphorylate axin and CKI } \alpha / \delta / \varepsilon \text { bind axin. Axin acts as a } \\
\text { scaffold for CKI phosphorylation of } \beta \text {-catenin and APC. }\end{array}$ & $\begin{array}{l}\text { Sakanaka et al. 1999; Kishida et al. } \\
\text { 2001; McKay et al. 2001a; Rubinfeld } \\
\text { et al. 2001; Gao et al. 2002; Amit et } \\
\text { al. 2002; Liu et al. } 2002\end{array}$ \\
\hline LEF-1 & $\begin{array}{l}\text { CKI } \delta / \varepsilon \text { binds and phosphorylates LEF-1, and this phosphorylation } \\
\text { disrupts LEF-1- } \beta \text {-catenin interaction. }\end{array}$ & Hammerlein et al. 2005 \\
\hline
\end{tabular}


increase in phosphatase activity) (Krishnan et al. 1997) or a decrease in phosphorylation of $\mathrm{Ci}$ by any of the kinases required for $\mathrm{Ci}$ proteolysis (e.g., a $\mathrm{Hh}$-induced decrease in the activity of PKA, CKI, or GSK3). Recent results suggest that $\mathrm{Hh}$ regulates the phosphorylation of $\mathrm{Ci}$ not by changing the activity of kinases, but by changing their subcellular localization (Zhang et al. 2005). Cos-2 associates with PKA, CKI, and GSK3 and is necessary for PKA phosphorylation of $\mathrm{Ci}$ in vivo, explaining why Cos-2 is required for Ci proteolysis (G. Wang et al. 2000). Upon Hh signaling, the association between Cos- 2 and all three kinases is disrupted, resulting in reduced phosphorylation of Ci-155 and its stabilization (Zhang et al. 2005).

While it is clear that phosphorylation of Smo in response to Hh can be blocked with PKA and CKI inhibitors, it is not known if $\mathrm{Hh}$ activates CKI activity in this context or if there is a connection between decreased phosphorylation of $\mathrm{Ci}$ and increased phosphorylation of Smo upon Hh signaling. In fact, it is possible that CKI phosphorylation of Smo is constitutive. By this model (Apionishev et al. 2005), phosphorylated Smo is degraded in the absence of $\mathrm{Hh}$ (and thus is not detected), and it is the accumulation of Smo and its localization to the cell surface that the Hh pathway regulates.

\section{Summary and future directions}

Multiple CKI family members positively and negatively regulate Wnt and Hh signaling by associating with and/ or phosphorylating multiple components of both pathways (Fig. 1; Tables 1, 2).] Targets for positive regulation of CKI include Wnt components Dvl, TCF, and LRP6 and the Hh component Smo. Negative regulation by CKI occurs via Wnt components APC and $\beta$-catenin and the $\mathrm{Hh}$ component $\mathrm{Ci}$, where phosphorylation leads to complete or partial proteolysis of $\beta$-catenin and $\mathrm{Ci}$, respectively, and inactivity of the pathway in the absence of ligand.

This raises major questions of how CKI regulates these pathways negatively and positively at the same time. There is some evidence that regulation of Wnt signaling is mediated by three distinct CKI family members; Wnt signaling may regulate these independently by different mechanisms. For example, Wnt activation of a phosphatase will presumably only affect $\mathrm{CKI} \varepsilon$, and not CKI $\gamma$ and $\mathrm{CKI} \alpha$, since only $\mathrm{CKI} \varepsilon$ undergoes inhibitory autophosphorylation. In the case of negative regulation of the pathway, it is not necessary that $\mathrm{CKI} \alpha$ is regulated at all by Wnt signaling to stabilize $\beta$-catenin, since blocking GSK3 $\beta$ activity is sufficient.

In the case of Hh signaling, which is potentially negatively and positively regulated by the same CKI family members, $\mathrm{CKI} \alpha$ and $\mathrm{CKI} \varepsilon$, the situation is less clear. There may be a switch in phosphorylation from Ci (the "negative" target) to Smo (the "positive" target) upon Hh signaling. Although Cos-2 binds to both $\mathrm{Ci}$ and Smo, it does not appear to mediate such a switch because the kinases are no longer associated with Cos-2 upon $\mathrm{Hh}$ signaling.

Another future question is the identification of specific phosphorylation sites in some CKI targets and a determination of whether these sites mediate changes upon Wnt signaling. This is not just a detail, but helps to firmly establish a protein as a direct target of a kinase. This will be difficult for full-length APC, where CKI potentially phosphorylates each of several repeated motifs on multiple sites, but may be possible in the case of Dvl. Loss-of-function data for a positive role of CKI $\varepsilon$ in Wnt signaling in vivo is relatively weak, and further understanding of Dvl phosphorylation will help address this. Also, Dvl has been identified as a branch point between canonical Wnt signaling and the planar cell polarity pathway, which are both mediated by the Wnt receptor Fz, and CKI phosphorylation of Dvl has been implicated in both pathways (McKay et al. 2001b; Cong et al. 2004).

Finally, RNAi has been a powerful tool for doing previously difficult or impossible loss-of-function studies in cell lines and in Drosophila when a conventional mutant is not available. While there are limitations to this approach, including problems with specificity between highly homologous genes (e.g., see Matsubayashi et al. 2004; Jia et al. 2005), hopefully this technique will help

Table 2. Demonstrated and proposed targets of CKI in Wnt signaling

\begin{tabular}{|c|c|c|}
\hline Target & Result & References \\
\hline \multicolumn{3}{|l|}{ A. Positive roles } \\
\hline Smo & $\begin{array}{l}\text { CKI } / \delta \text { phosphorylate Smo in vitro and in cultured cells. } \\
\text { Phosphorylation of Smo by CKI is required for Smo transduction of } \\
\text { Hh signal in Drosophila embryos, wing discs, and cultured cells. } \\
\text { Effects of CKI phosphorylation on Smo stability is less clear; } \\
\text { however, results with phosphomimetic mutations suggest that } \\
\text { phosphorylation stabilizes Smo. These mutations lead to constitutive } \\
\text { membrane localization of Smo and phosphorylation of Fu, Su(fu), and } \\
\text { Cos-2 in the absence of Hh signaling. }\end{array}$ & $\begin{array}{l}\text { Jia et al. 2004; Zhang et al. 2004; } \\
\text { Apionishev et al. } 2005\end{array}$ \\
\hline \multicolumn{3}{|l|}{ B. Negative roles } \\
\hline $\mathrm{Ci}$ & $\begin{array}{l}\text { CKI phosphorylates Ci in vitro on sites primed by PKA and GSK3. } \\
\text { Mutations in CKI sites prevent Ci repressor formation. CKI } \alpha \text { and } \\
\text { CKI } \varepsilon \text { cooperate in Ci processing in wing discs. CKI phosphorylation } \\
\text { of Ci is required for Slimb binding, leading to ubiquitination and } \\
\text { processing by the proteasome. }\end{array}$ & $\begin{array}{l}\text { Price and Kalderon 2002; Lum et al } \\
\text { 2003; Jia et al. 2005; Smelkinson } \\
\text { and Kalderon } 2006\end{array}$ \\
\hline
\end{tabular}


to clarify some of the outstanding questions about the role of CKI in Wnt and Hh signaling.

\section{Acknowledgments}

I thank Helen and David Strutt for helpful comments on the manuscript and the reviewers for many useful suggestions. I also thank Davidson et al. (2005) and Jia et al. (2005) for copies of their manuscripts prior to publication. M.A.P. is supported by a Wellcome Trust University Award.

\section{References}

Amit, S., Hatzubai, A., Birman, Y., Andersen, J.S., Ben-Shushan, E., Mann, M., Ben-Neriah, Y., and Alkalay, I. 2002. Axinmediated CKI phosphorylation of $\beta$-catenin at Ser 45: A molecular switch for the Wnt pathway. Genes \& Dev. 16: 10661076.

Apionishev, S., Katanayeva, N.M., Marks, S.A., Kalderon, D., and Tomlinson, A. 2005. Drosophila Smoothened phosphorylation sites essential for Hedgehog signal transduction. Nat. Cell Biol. 7: 86-92.

Aza-Blanc, P., Ramirez-Weber, F.A., Laget, M.P., Schwartz, C., and Kornberg, T.B. 1997. Proteolysis that is inhibited by hedgehog targets Cubitus interruptus protein to the nucleus and converts it to a repressor. Cell 89: 1043-1053.

Aza-Blanc, P., Lin, H.Y., Ruiz i Altaba, A., and Kornberg, T.B. 2000. Expression of the vertebrate Gli proteins in Drosophila reveals a distribution of activator and repressor activities. Development 127: 4293-4301.

Chen, Y., Gallaher, N., Goodman, R.H., and Smolik, S.M. 1998. Protein kinase A directly regulates the activity and proteolysis of Cubitus interruptus. Proc. Natl. Acad. Sci. 95: 23492354.

Chen, C.H., von Kessler, D.P., Park, W., Wang, B., Ma, Y., and Beachy, P.A. 1999. Nuclear trafficking of Cubitus interruptus in the transcriptional regulation of Hedgehog target gene expression. Cell 98: 305-316.

Chen, Y., Cardinaux, J.R., Goodman, R.H., and Smolik, S.M. 1999. Mutants of Cubitus interruptus that are independent of PKA regulation are independent of Hedgehog signaling. Development 126: 3607-3616.

Chijiwa, T., Hagiwara, M., and Hidaka, H. 1989. A newly synthesized selective casein kinase I inhibitor, N-(2-aminoethyl)-5-chloroisoquinoline-8-sulfonamide, and affinity purification of casein kinase I from bovine testis. J. Biol. Chem. 264: 4924-4927.

Concordet, J.P., Lewis, K.E., Moore, J.W., Goodrich, L.V., Johnson, R.L., Scott, M.P., and Ingham, P.W. 1996. Spatial regulation of a zebrafish patched homologue reflects the roles of Sonic hedgehog and protein kinase A in neural tube and somite patterning. Development 122: 2835-2846.

Cong, F., Schweizer, L., and Varmus, H. 2004. Casein kinase I $\varepsilon$ modulates the signaling specificities of dishevelled. Mol. Cell. Biol. 24: 2000-2011.

Dai, P., Akimaru, H., and Ishii, S. 2003. A hedgehog-responsive region in the Drosophila wing disc is defined by debra-mediated ubiquitination and lysosomal degradation of Ci. Dev. Cell 4: 917-928.

DasGupta, R., Kaykas, A., Moon, R.T., and Perrimon, N. 2005. Functional genomic analysis of the Wnt-wingless signaling pathway. Science 308: 826-833.

Davidson, G., Wu, W., Shen, J., Bilic, J., Fenger, U., Stannek, P., Glinka, A., and Niehrs, C. 2005. Casein kinase $1 \gamma$ couples
Wnt receptor activation to cytoplasmic signal transduction. Nature 438: 867-872.

Denef, N., Neubuser, D., Perez, L., and Cohen, S.M. 2000. Hedgehog induces opposite changes in turnover and subcellular localization of patched and smoothened. Cell 102: $521-$ 531.

Flotow, H. and Roach, P.J. 1989. Synergistic phosphorylation of rabbit muscle glycogen synthase by cyclic AMP-dependent protein kinase and casein kinase I. Implications for hormonal regulation of glycogen synthase. J. Biol. Chem. 264: 9126-9128.

_ 1991. Role of acidic residues as substrate determinants for casein kinase I. J. Biol. Chem. 266: 3724-3727.

Flotow, H., Graves, P.R., Wang, A.Q., Fiol, C.J., Roeske, R.W., and Roach, P.J. 1990. Phosphate groups as substrate determinants for casein kinase I action. I. Biol. Chem. 265: 14264-14269.

Gao, Z.H., Seeling, J.M., Hill, V., Yochum, A., and Virshup, D.M. 2002. Casein kinase I phosphorylates and destabilizes the $\beta$-catenin degradation complex. Proc. Natl. Acad. Sci. 99: $1182-1187$.

Grammer, T.C., Liu, K.J., Mariani, F.V., and Harland, R.M. 2000. Use of large-scale expression cloning screens in the Xenopus laevis tadpole to identify gene function. Dev. Biol. 228: $197-210$.

Gross, S.D. and Anderson, R.A. 1998. Casein kinase I: Spatial organization and positioning of a multifunctional protein kinase family. Cell Signal 10: 699-711.

Ha, N.C., Tonozuka, T., Stamos, J.L., Choi, H.J., and Weis, W.I. 2004. Mechanism of phosphorylation-dependent binding of APC to $\beta$-catenin and its role in $\beta$-catenin degradation. Mol. Cell 15: 511-521.

Hammerlein, A., Weiske, J., and Huber, O. 2005. A second protein kinase CK1-mediated step negatively regulates Wnt signalling by disrupting the lymphocyte enhancer factor- $1 / \beta$ catenin complex. Cell. Mol. Life Sci. 62: 606-618.

Hammerschmidt, M., Bitgood, M.J., and McMahon, A.P. 1996. Protein kinase A is a common negative regulator of Hedgehog signaling in the vertebrate embryo. Genes \& Dev. 10: 647-658.

Hanks, S.K. and Hunter, T. 1995. Protein kinases 6. The eukaryotic protein kinase superfamily: Kinase (catalytic) domain structure and classification. FASEB J. 9: 576-596.

He, X., Semenov, M., Tamai, K., and Zeng, X. 2004. LDL receptor-related proteins 5 and 6 in Wnt/ $\beta$-catenin signaling: Arrows point the way. Development 131: 1663-1677.

Hino, S., Michiue, T., Asashima, M., and Kikuchi, A. 2003. Casein kinase I $\varepsilon$ enhances the binding of Dvl-1 to Frat-1 and is essential for Wnt-3a-induced accumulation of $\beta$-catenin. J. Biol. Chem. 278: 14066-14073.

Hooper, J.E. and Scott, M.P. 2005. Communicating with Hedgehogs. Nat. Rev. Mol. Cell. Biol. 6: 306-317.

Hsu, W., Zeng, L., and Costantini, F. 1999. Identification of a domain of Axin that binds to the serine/threonine protein phosphatase $2 \mathrm{~A}$ and a self-binding domain. J. Biol. Chem. 274: 3439-3445.

Ingham, P.W. and McMahon, A.P. 2001. Hedgehog signaling in animal development: Paradigms and principles. Genes \& Dev. 15: 3059-3087.

Jia, J., Amanai, K., Wang, G., Tang, J., Wang, B., and Jiang, J. 2002. Shaggy/GSK3 antagonizes Hedgehog signalling by regulating Cubitus interruptus. Nature 416: 548-552.

Jia, J., Tong, C., Wang, B., Luo, L., and Jiang, J. 2004. Hedgehog signalling activity of Smoothened requires phosphorylation by protein kinase A and casein kinase I. Nature 432: 10451050 . 
Jia, J., Zhang, L., Zhang, Q., Tong, C., Wang, B., Hou, F., Amanai, K., and Jiang, J. 2005. Phosphorylation by double-time/ $\mathrm{CKI} \varepsilon$ and $\mathrm{CKI} \alpha$ targets Cubitus interruptus for $\mathrm{Slimb} / \beta$ TRCP-mediated proteolytic processing. Dev. Cell 9: 819-830.

Jiang, J. and Struhl, G. 1998. Regulation of the Hedgehog and Wingless signalling pathways by the F-box/WD40-repeat protein Slimb. Nature 391: 493-496.

Kalderon, D. 2002. Similarities between the Hedgehog and Wnt signaling pathways. Trends Cell Biol. 12: 523-531.

Kishida, M., Hino, S., Michiue, T., Yamamoto, H., Kishida, S., Fukui, A., Asashima, M., and Kikuchi, A. 2001. Synergistic activation of the Wnt signaling pathway by Dvl and casein kinase I $\varepsilon$. J. Biol. Chem. 276: 33147-33155.

Knippschild, U., Gocht, A., Wolff, S., Huber, N., Lohler, J., and Stoter, M. 2005. The casein kinase 1 family: Participation in multiple cellular processes in eukaryotes. Cell Signal 17: 675-689.

Krishnan, V., Pereira, F.A., Qiu, Y., Chen, C.H., Beachy, P.A., Tsai, S.Y., and Tsai, M.J. 1997. Mediation of Sonic hedgehoginduced expression of COUP-TFII by a protein phosphatase. Science 278: 1947-1950.

Lee, J.S., Ishimoto, A., and Yanagawa, S. 1999. Characterization of mouse dishevelled (Dvl) proteins in Wnt/Wingless signaling pathway. J. Biol. Chem. 274: 21464-21470.

Lee, E., Salic, A., and Kirschner, M.W. 2001. Physiological regulation of $\beta$-catenin stability by Tcf3 and CK1є. J. Cell Biol. 154: 983-993.

Li, L., Yuan, H., Weaver, C.D., Mao, J., Farr III, G.H., Sussman, D.J., Jonkers, J., Kimelman, D., and Wu, D. 1999. Axin and Fratl interact with dvl and GSK, bridging Dvl to GSK in Wnt-mediated regulation of LEF-1. EMBO J. 18: 4233-4240.

Liu, C., Li, Y., Semenov, M., Han, C., Baeg, G.H., Tan, Y., Zhang, Z., Lin, X., and He, X. 2002. Control of $\beta$-catenin phosphorylation/degradation by a dual-kinase mechanism. Cell 108: 837-847.

Logan, C.Y. and Nusse, R. 2004. The Wnt signaling pathway in development and disease. Annu. Rev. Cell Dev. Biol. 20: 781-810.

Lum, L., Yao, S., Mozer, B., Rovescalli, A., Von Kessler, D., Nirenberg, M., and Beachy, P.A. 2003. Identification of Hedgehog pathway components by RNAi in Drosophila cultured cells. Science 299: 2039-2045.

Marin, O., Bustos, V.H., Cesaro, L., Meggio, F., Pagano, M.A., Antonelli, M., Allende, C.C., Pinna, L.A., and Allende, J.E. 2003. A noncanonical sequence phosphorylated by casein kinase 1 in $\beta$-catenin may play a role in casein kinase 1 targeting of important signaling proteins. Proc. Natl. Acad. Sci. 100: 10193-10200.

Mashhoon, N., DeMaggio, A.J., Tereshko, V., Bergmeier, S.C., Egli, M., Hoekstra, M.F., and Kuret, J. 2000. Crystal structure of a conformation-selective casein kinase-1 inhibitor. J. Biol. Chem. 275: 20052-20060.

Matsubayashi, H., Sese, S., Lee, J.S., Shirakawa, T., Iwatsubo, T., Tomita, T., and Yanagawa, S. 2004. Biochemical characterization of the Drosophila wingless signaling pathway based on RNA interference. Mol. Cell. Biol. 24: 2012-2024.

McKay, R.M., Peters, J.M., and Graff, J.M. 2001a. The casein kinase I family in Wnt signaling. Dev. Biol. 235: 388-396.

- 2001b. The casein kinase I family: Roles in morphogenesis. Dev. Biol. 235: 378-387.

Methot, N. and Basler, K. 1999. Hedgehog controls limb development by regulating the activities of distinct transcriptional activator and repressor forms of Cubitus interruptus. Cell 96: 819-831.

Moon, R.T., Brown, J.D., and Torres, M. 1997. WNTs modulate cell fate and behavior during vertebrate development. Trends Genet. 13: 157-162.

Morrison, D.K., Murakami, M.S., and Cleghon, V. 2000. Protein kinases and phosphatases in the Drosophila genome. J. Cell Biol. 150: F57-F62.

Nash, P., Tang, X., Orlicky, S., Chen, Q., Gertler, F.B., Mendenhall, M.D., Sicheri, F., Pawson, T., and Tyers, M. 2001. Multisite phosphorylation of a CDK inhibitor sets a threshold for the onset of DNA replication. Nature 414: 514-521.

Pasca di Magliano, M. and Hebrok, M. 2003. Hedgehog signalling in cancer formation and maintenance. Nat. Rev. Cancer 3: 903-911.

Peters, J.M., McKay, R.M., McKay, J.P., and Graff, J.M. 1999. Casein kinase I transduces Wnt signals. Nature 401: 345350.

Plowman, G.D., Sudarsanam, S., Bingham, J., Whyte, D., and Hunter, T. 1999. The protein kinases of Caenorhabditis elegans: A model for signal transduction in multicellular organisms. Proc. Natl. Acad. Sci. 96: 13603-13610.

Polakis, P. 1999. The oncogenic activation of $\beta$-catenin. Curr. Opin. Genet. Dev. 9: 15-21.

- 2002. Casein kinase 1: A Wnt'er of disconnect. Curr. Biol. 12: R499-R501.

Price, M.A. and Kalderon, D. 1999. Proteolysis of Cubitus interruptus in Drosophila requires phosphorylation by protein kinase A. Development 126: 4331-4339.

- 2002. Proteolysis of the Hedgehog signaling effector Cubitus interruptus requires phosphorylation by glycogen synthase kinase 3 and casein kinase 1. Cell 108: 823-835.

Pulgar, V., Marin, O., Meggio, F., Allende, C.C., Allende, J.E., and Pinna, L.A. 1999. Optimal sequences for non-phosphatedirected phosphorylation by protein kinase CK1 (casein kinase-1)-A re-evaluation. Eur. J. Biochem. 260: 520-526.

Reya, T. and Clevers, H. 2005. Wnt signalling in stem cells and cancer. Nature 434: 843-850.

Rivers, A., Gietzen, K.F., Vielhaber, E., and Virshup, D.M. 1998. Regulation of casein kinase I $\varepsilon$ and casein kinase I $\delta$ by an in vivo futile phosphorylation cycle. J. Biol. Chem. 273: 1598015984.

Rubinfeld, B., Tice, D.A., and Polakis, P. 2001. Axin-dependent phosphorylation of the adenomatous polyposis coli protein mediated by casein kinase 1ع. J. Biol. Chem. 276: 3903739045.

Sakanaka, C., Leong, P., Xu, L., Harrison, S.D., and Williams, L.T. 1999. Casein kinase I $\varepsilon$ in the wnt pathway: Regulation of $\beta$-catenin function. Proc. Natl. Acad. Sci. 96: $12548-12552$.

Seeling, J.M., Miller, J.R., Gil, R., Moon, R.T., White, R., and Virshup, D.M. 1999. Regulation of $\beta$-catenin signaling by the B56 subunit of protein phosphatase 2A. Science 283: 20892091.

Smelkinson, M.G. and Kalderon, D. 2006. Processing of the Drosophila Hedgehog signaling effector Ci-155 to the repressor Ci-75 is mediated by direct binding to the SCF component Slimb. Curr. Biol. 16: 110-116.

Swiatek, W., Tsai, I.C., Klimowski, L., Pepler, A., Barnette, J., Yost, H.J., and Virshup, D.M. 2004. Regulation of casein kinase I $\varepsilon$ activity by Wnt signaling. J. Biol. Chem. 279: 1301113017.

Taipale, J. and Beachy, P.A. 2001. The Hedgehog and Wnt signalling pathways in cancer. Nature 411: 349-354.

Tamai, K., Zeng, X., Liu, C., Zhang, X., Harada, Y., Chang, Z., and He, X. 2004. A mechanism for Wnt coreceptor activation. Mol. Cell 13: 149-156.

van Amerongen, R., Nawijn, M., Franca-Koh, J., Zevenhoven, J., van der Gulden, H., Jonkers, J., and Berns, A. 2005. Frat is 
dispensable for canonical Wnt signaling in mammals. Genes \& Dev. 19: 425-430.

von Mering, C. and Basler, K. 1999. Distinct and regulated activities of human Gli proteins in Drosophila. Curr. Biol. 9: $1319-1322$

Wang, B. and Li, Y. 2006. Evidence for the direct involvement of $\beta-\mathrm{TrCP}$ in Gli3 protein processing. Proc. Natl. Acad. Sci. 103: $33-38$.

Wang, B., Fallon, J.F., and Beachy, P.A. 2000. Hedgehog-regulated processing of Gli3 produces and anterior/posterior repressor gradient in the developing vertebrate limb. Cell 100: 423-434.

Wang, G., Amanai, K., Wang, B., and Jiang, J. 2000. Interactions with Costal2 and suppressor of fused regulate nuclear translocation and activity of Cubitus interruptus. Genes \& Dev. 14: 2893-2905.

Weaver, C. and Kimelman, D. 2004. Move it or lose it: Axis specification in Xenopus. Development 131: 3491-3499.

Winston, J.T., Strack, P., Beer-Romero, P., Chu, C.Y., Elledge, S.J., and Harper, J.W. 1999. The SCF ${ }^{\beta-\text { TRCP}_{-}}$ubiquitin ligase complex associates specifically with phosphorylated de-

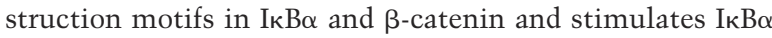
ubiquitination in vitro. Genes \& Dev. 13: 270-283.

Xing, Y., Clements, W.K., Kimelman, D., and Xu, W. 2003. Crystal structure of a $\beta$-catenin/axin complex suggests a mechanism for the $\beta$-catenin destruction complex. Genes \& Dev. 17: 2753-2764.

Xing, Y., Clements, W.K., Le Trong, I., Hinds, T.R., Stenkamp, R., Kimelman, D., and $\mathrm{Xu}, \mathrm{W}$. 2004. Crystal structure of a $\beta$-catenin/APC complex reveals a critical role for APC phosphorylation in APC function. Mol. Cell 15: 523-533.

Yanagawa, S., van Leeuwen, F., Wodarz, A., Klingensmith, J., and Nusse, R. 1995. The dishevelled protein is modified by wingless signaling in Drosophila. Genes \& Dev. 9: 10871097.

Yanagawa, S., Matsuda, Y., Lee, J.S., Matsubayashi, H., Sese, S., Kadowaki, T., and Ishimoto, A. 2002. Casein kinase I phosphorylates the Armadillo protein and induces its degradation in Drosophila. EMBO J. 21: 1733-1742.

Yost, C., Farr III, G.H., Pierce, S.B., Ferkey, D.M., Chen, M.M., and Kimelman, D. 1998. GBP, an inhibitor of GSK-3, is implicated in Xenopus development and oncogenesis. Cell 93: 1031-1041.

Zeng, X., Tamai, K., Doble, B., Li, S., Huang, H., Habas, R., Okamura, H., Woodgett, J., and He, X. 2005. A dual-kinase mechanism for Wnt co-receptor phosphorylation and activation. Nature 438: 873-877.

Zhang, C., Williams, E.H., Guo, Y., Lum, L., and Beachy, P.A. 2004. Extensive phosphorylation of Smoothened in Hedgehog pathway activation. Proc. Natl. Acad. Sci. 101: 1790017907.

Zhang, W., Zhao, Y., Tong, C., Wang, G., Wang, B., Jia, J., and Jiang, J. 2005. Hedgehog-regulated Costal2-kinase complexes control phosphorylation and proteolytic processing of Cubitus interruptus. Dev. Cell 8: 267-278.

Zhu, J., Shibasaki, F., Price, R., Guillemot, J.C., Yano, T., Dotsch, V., Wagner, G., Ferrara, P., and McKeon, F. 1998. Intramolecular masking of nuclear import signal on NF-AT4 by casein kinase I and MEKK1. Cell 93: 851-861. 


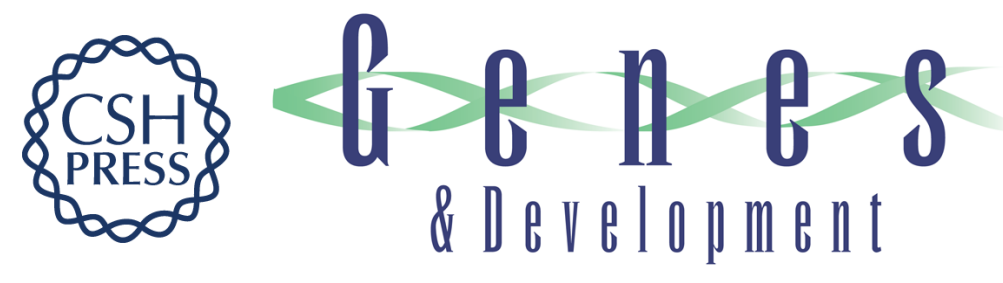

\title{
CKI, there's more than one: casein kinase I family members in Wnt and Hedgehog signaling
}

\author{
Mary Ann Price
}

Genes Dev. 2006, 20:

Access the most recent version at doi:10.1101/gad.1394306

$\begin{array}{ll}\text { References } & \text { This article cites } 85 \text { articles, } 43 \text { of which can be accessed free at: } \\ \text { http://genesdev.cshlp.org/content/20/4/399.full.html\#ref-list-1 }\end{array}$

License Email Alerting
Service

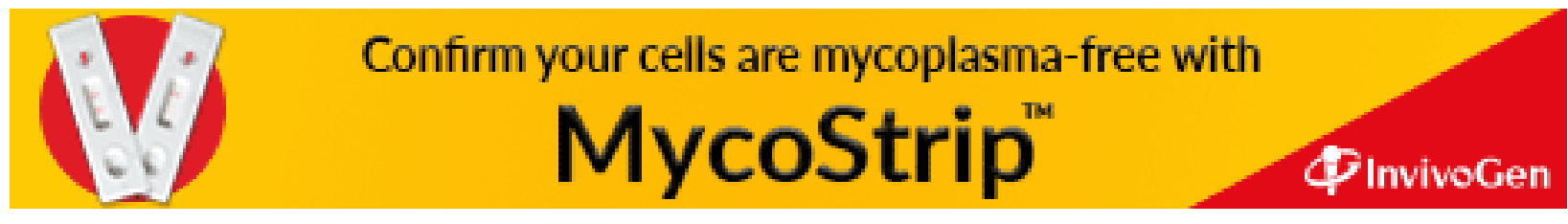

